\title{
Establishment of a Rodent Model of HIV-Associated Sensory Neuropathy
}

\author{
Sanjay C. Keswani, ${ }^{1}$ Christelene Jack, ${ }^{1}$ Chunhua Zhou, ${ }^{1}$ and Ahmet Höke ${ }^{1,2}$ \\ Departments of ${ }^{1}$ Neurology and ${ }^{2}$ Neuroscience, Johns Hopkins University School of Medicine, Baltimore, Maryland 21287
}

\begin{abstract}
Human immunodeficiency virus (HIV)-associated sensory neuropathy (SN) is the most common neurological complication of HIV infection in the current highly active antiretroviral therapy era. The painful sensory neuropathy is associated with the use of dideoxynucleoside antiretrovirals, and its development limits the choice of antiretroviral drugs in affected patients. There are presently no effective therapies for HIV-SN, and moreover there has been no robust animal model of HIV-SN in which candidate therapeutic agents can be tested. In this paper, we show that we have established a rodent model of HIV-SN by oral administration of a dideoxynucleoside drug, didanosine, to transgenic mice expressing the HIV coat protein gp120 under a GFAP promoter. The neuropathy in these rodents is characterized by distal degeneration of unmyelinated sensory axons, similar to the "dying back" pattern of C-fiber loss seen in patients with HIV-SN. This model will be useful in examining mechanisms of distal axonal degeneration and testing potential neuroprotective compounds that may prevent development of the sensory neuropathy.
\end{abstract}

Key words: HIV; peripheral neuropathy; animal model; gp120; DDI; dideoxynucleoside

\section{Introduction}

Human immunodeficiency virus (HIV)-associated sensory neuropathy (SN) is the most common neurological complication of HIV infection, symptomatically affecting over one third of patients with HIV (for review, see Keswani et al., 2002; Höke and Cornblath, 2005). The symptoms of HIV-SN are dominated by neuropathic pain, which is often excruciating. The pain is usually most severe on the soles of the feet, making walking difficult. HIV-SN is characterized pathologically by distal degeneration of long axons, in a pattern termed "dying back," because of the observation that the distal regions of the fibers degenerate first, with centripetal progression (Mah et al., 1988; Miller et al., 1988). Characteristically, there is prominent involvement of unmyelinated $\mathrm{C}$ fibers, as shown by reduced intraepidermal nerve fiber densities on punch skin biopsies of the distal leg in patients with HIV-SN. Of interest, the degree of intraepidermal nerve fiber (IENF) loss correlates with the severity of neuropathic pain in patients with HIV-SN (Polydefkis et al., 2002). There are presently no effective therapies for HIV-SN, and moreover there has been no robust animal model of HIV-SN in which candidate therapeutic agents could be tested. This study aimed to develop such a model of HIV-SN.

Histopathological studies of HIV-SN have revealed, in addition to a "dying back" sensory axonopathy, the presence of activated HIV-infected macrophages in the dorsal root ganglia

\footnotetext{
Received July 23, 2006; revised Aug. 20, 2006; accepted Sept. 4, 2006.

This work was supported by National Institutes of Health Grants NS43991, MH70056 (to A.H.), and NS47972 (to

S.C.K.). We thank Alene Carteret and Carol Rubright for their technical assistance.

Correspondence should be addressed to Dr. Ahmet Höke, Johns Hopkins Hospital, 600 North Wolfe Street, Path 509, Baltimore, MD 21287. E-mail: ahoke@jhmi.edu.

S.C. Keswani's present address: Amgen Inc., One Amgen Center Drive, Thousand 0aks, CA 91320-1799. DOI:10.1523/JNEUROSCI.3135-06.2006

Copyright $\odot 2006$ Society for Neuroscience $\quad$ 0270-6474/06/2610299-06\$15.00/0
}

(DRG) and peripheral nerve. Akin to the situation in HIV dementia, neuronal infection by HIV occurs rarely, if at all, in the DRG of patients with HIV-SN (Pardo et al., 2001). It is thus hypothesized that the sensory axonopathy seen in HIV-SN results from neurotoxicity by soluble mediators released by infiltrating HIV-infected macrophages. These mediators include secreted viral proteins such as the HIV-1 envelope glycoprotein gp120, which has been shown to be a potent neurotoxin, capable of causing axonal degeneration and, at higher doses, neuronal death (Apostolski et al., 1993; Dawson et al., 1993). Transgenic mice expressing secretable gp120 in astrocytes (under the control of a modified GFAP gene) have neuropathological abnormalities in their brains that are similar to those found in patients with HIV dementia (Toggas et al., 1994). These abnormalities include widespread degeneration of dendrites, loss of presynaptic terminals, reactive astrocytosis, and microglial nodules. In addition, these mice display reduced hippocampal long-term potentiation and age-dependent behavioral deficits suggestive of cognitive impairment.

A major risk factor for the development of HIV-SN is the use of dideoxynucleoside (DDX) reverse transcriptase inhibitors. These agents, which include zalcitabine (DDC), didanosine (DDI), and stavudine (d4T), are known to cause neuronal mitochondrial dysfunction and axonal degeneration in primary dorsal root ganglion cultures (Keswani et al., 2003a). It has, however, been difficult to establish an animal model of DDX-induced peripheral neuropathy, despite using high doses of DDX agents (J. C. McArthur, personal communication; A. Höke unpublished observation), raising the hypothesis that pre-existing injury to sensory axons or cell bodies of DRG neurons by HIV viral proteins such as gp 120, results in vulnerability to DDX-induced neurotoxicity ("double-hit hypothesis"). In this study, we aimed to establish an animal model of HIV-SN by administering DDI 
orally to gp120 transgenic mice. Expression of gp120 in these mice is under the control of GFAP promoter. As astrocytes and Schwann cells are the main cells expressing GFAP, gp120 is thus expressed and released by astrocytes in the CNS and Schwann cells in the peripheral nervous system (PNS). We show that DDI exposure to such mice results in distal axonal degeneration affecting small, unmyelinated fibers, similar to the neuropathology noted in HIV-SN. This small rodent model may be used to evaluate potential therapeutic strategies for HIV-SN.

\section{Materials and Methods}

All experiments involving animals were conducted under the protocols approved by the Johns Hopkins University Animal Care and Use Committee according to guidelines established by National Institutes of Health and American Association for the Accreditation of Laboratory Animal Care. Breeding pairs of the transgenic mice expressing gp120 under the GFAP promoter (line A45) were kindly provided by Dr. Lennart Mucke.

Genotyping, RT-PCR and Western, blotting. The presence of gp120 transgene was confirmed using methods according to the reports published previously (Mucke et al., 1995). The total RNA was isolated from the sciatic nerve, spinal cord, and brain using the Trizol method and reverse transcription (RT)-PCR for gp120 mRNA was done using standard protocols with the following primers: $5^{\prime}$-gcgggagaatgataatggag- $3^{\prime}$ (forward) and 5'-tatgggaattggctcaaagg-3' (backward). Confirmation of expression of gp120 in the sciatic nerve and spinal cord was done with Western blotting of tissue extracts using anti-gp120 antibody (Abcam, Cambridge, MA; catalog number ab20262).

Animal studies. Littermates of gp120 transgenic mice, aged 2 months, received either DDI dissolved in drinking water or vehicle control (PBS) for a duration of 4 weeks. The concentration of DDI in the water was 5 $\mathrm{mg} / \mathrm{ml}$. Total daily consumption of water was carefully measured and total daily dose per mouse was calculated for the duration of the study; the average daily dose per mouse was $25 \mathrm{mg} / \mathrm{d}$. The water bottle containing DDI was replenished once a week. In control experiments, mice of the same background (B6/SJL) and age were purchased and treated similarly with either DDI-containing water or vehicle control. The number of animals in each group was $8-10$.

Behavioral and electrophysiological testing was done at baseline before the start of the study and repeated at the end of 4 weeks. Sensory testing for thermal sensation was done on the left hindpaw using a hot plate analgesia meter (IITC Life Sciences, Woodland Hills, CA) as described previously (Levy et al., 1999). Motor-strength testing was done in the hindpaw using a Stoelting (Wood Dale, IL) grip strength meter according to established protocols (McKeown et al., 1975). Coordinated motor testing was done using a rotorod apparatus (Rotamex; Columbus Instruments, Columbus, $\mathrm{OH}$ ) according to standard protocols (Hymson and Hynes, 1982). Sensory nerve conduction studies were done under inhalation anesthesia according to standard methods as described previously (Levy et al., 2000). Briefly, sensory nerve action potentials (SNAPs) were recorded at the base of the tail after stimulation at $5 \mathrm{~cm}$ distal to the recording site. Responses to 20 supramaximal stimulations were averaged and recorded using PowerLab 8/SP hardware and the integrated Chart software (AD Instruments, Colorado Springs, $C O$ ) in an iMac computer (Apple Computers, Cupertino, CA). SNAP amplitude and onset latency were measured individually for each animal and the sensory conduction velocities were calculated. Similarly, the motor nerve conduction studies were done using the same setup. Subdermal recording electrodes were placed in the intrinsic foot muscles of the hindlimb and the stimulating electrodes were placed at the sciatic notch. Compound motor action potentials (CMAPs) and onset latencies were recorded for each animal individually and the maximum CMAP response was used in the calculations.

Histological evaluation. At the end of 4 weeks, the animals were deeply anesthetized by inhalation anesthesia and plantar pads were harvested by punch biopsy for evaluation of IENF density according to standard protocols (McCarthy et al., 1995; Polydefkis et al., 2002). Briefly, the skins were placed in periodate-lysine-paraformaldehyde fixative for $18 \mathrm{~h}$,
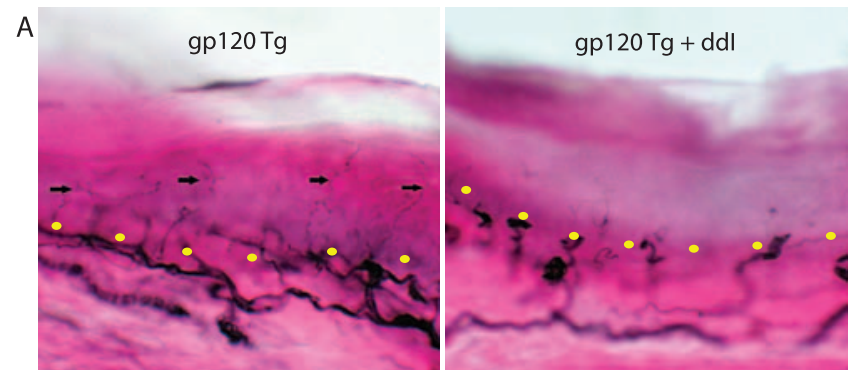

B

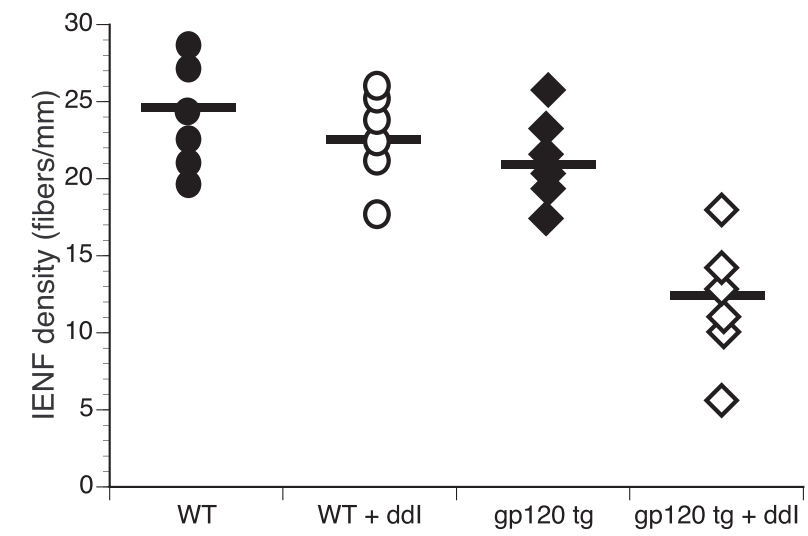

Figure 1. Oral administration of the antiretroviral drug DDI to gp120 transgenic mice induces cutaneous denervation. DDI administration to gp120 transgenic mice resulted in a decreased IENF density $(p<0.05)$ in the plantar footpads of gp120 transgenic mice. $A$, Representative PGP 9.5-stained skin biopsies from the plantar footpads of gp120 transgenic mice with and without DDI exposure. The black arrows show individual IENFs, and the yellow dots highlight the dermal-epidermal junction. $\boldsymbol{B}$, Quantitation of plantar footpad IENF densities for wild-type and gp120 transgenic mice \pm DDI exposure. Note that in contrast to gp120 transgenic mice, DDI exposure to age-matched wild-type controls did not reduce IENF density. In addition, there was no significant difference in IENF density between wild-type controls and gp120 transgenics not exposed to DDI. $n=8$ animals per group; $p<0.05$ compared with other groups.

transferred to cryoprotectant (20\% glycerin), sectioned in a freezing microtome at $50-\mu \mathrm{m}$-thick sections, and stained with a pan-axonal marker anti-protein gene product (PGP) 9.5 antibody (Biogenesis, Kingston, $\mathrm{NH}$ ). The number of intraepidermal unmyelinated axons was counted in a blinded manner and the density of IENFs per millimeter of skin was determined.

After the punch biopsies, animals were perfused with $4 \%$ paraformaldehyde and tissues were harvested for ultrastructural analysis. The sciatic nerves at the mid-thigh level, whole feet with distal plantar nerves, and the whole spinal column with intact dorsal root ganglia, cauda equina, and spinal cord were postfixed in $4 \%$ paraformaldehyde/3\% glutaraldehyde for $3 \mathrm{~d}$. The tissues were transferred to Sorenson's buffer and kept at $4^{\circ} \mathrm{C}$ until further processing. The spinal columns and feet were decalcified and then together with the sciatic nerves, processed for plastic embedding according to standard protocols as described previously (Höke et al., 2003). Toluidine blue-stained $1-\mu \mathrm{m}$-thick sections were used to evaluate the large myelinated fibers using stereological methods and thin sections were prepared for electron microscopic evaluation of unmyelinated axons. The numbers of unmyelinated axons per Remak Schwann cell were counted using unbiased sampling methods as described previously (Höke et al., 2003). ANOVA with correction for multiple comparisons was used for statistical analysis.

\section{Results}

gp120 expression in the peripheral nerve, spinal cord, and brain of GFAP-gp120 transgenic mice

Consistent with the previous literature, we noted that the gp120 protein and mRNA were present in the CNS and PNS of GFAPgp120 transgenic mice (and absent in wild-type littermate con- 

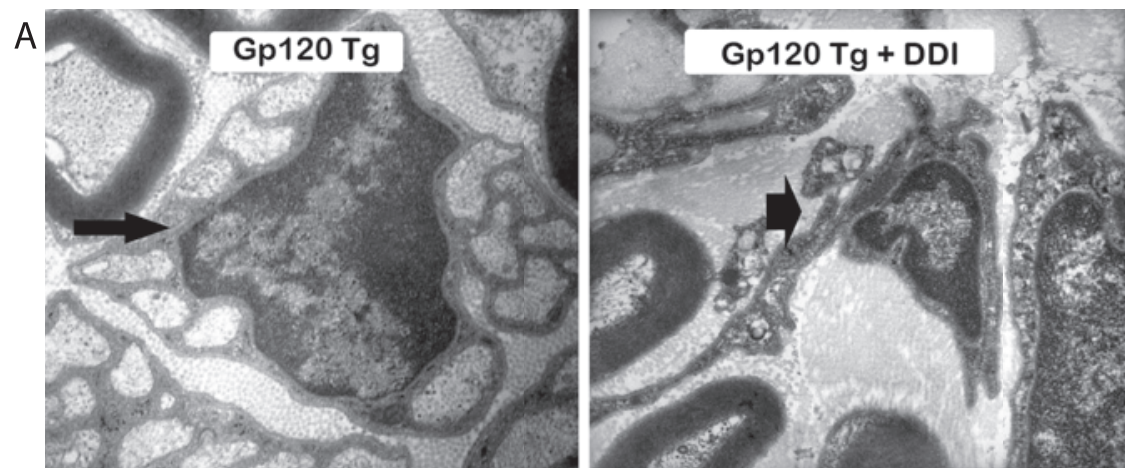

B

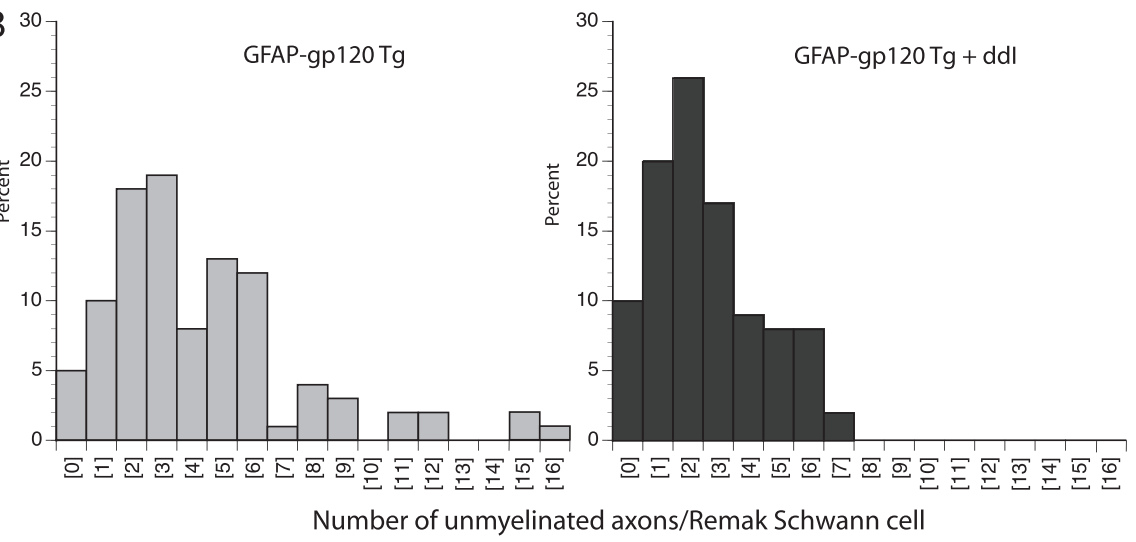

Figure 2. Administration of DDI to gp120 transgenic mice induces loss of unmyelinated axons in distal plantar nerves. $\boldsymbol{A}$, Representative electron micrographs of Remak bundles from the distal plantar nerves from gp120 transgenic mice \pm DDI exposure are shown. Normal Remak bundles containing unmyelinated axons are seen in mice not given DDI (small arrow). In DDI-treated mice, "empty" Remak bundles (i.e., Schwann cells devoid of unmyelinated axons) (large arrow) are seen. $\boldsymbol{B}$, In mice given DDI, Remak bundles contain fewer unmyelinated axons (i.e., the histogram is shifted to the left). $p<0.05 ; n=8$ animals per group.

trols). This was determined using RT-PCR analysis for gp120 mRNA and Western blot analysis for Gp120 protein in harvested sciatic nerve, spinal cord, and brain (data not shown).

Oral administration of the antiretroviral drug DDI to GFAP-gp120 transgenic mice results in reduced intraepidermal nerve fiber density

Intraepidermal nerve fibers, which represent the terminals of $\mathrm{C}$ (nociceptive) fibers, are known to degenerate in patients with HIV-SN (Polydefkis et al., 2002). Measurement of IENF density in PGP 9.5-stained punch skin biopsies is a useful way to evaluate the integrity of these distal unmyelinated axons in both rodents and humans, and is increasingly being used as an outcome measure in clinical trials of neuroprotective agents in HIV-SN. There was no significant difference in IENF density in the plantar footpad between 2-month-old gp120 transgenic mice and agematched wild-type controls (Fig. 1). Oral administration of DDI for 1 month to wild-type mice did not significantly alter IENF density. In contrast, similar DDI exposure in gp120 transgenic mice resulted in a significant reduction of IENF density in the plantar footpad $(p<0.05)$.

Oral administration of DDI to GFAP-gp120 transgenic mice induces loss of unmyelinated axons in distal plantar nerves

Rodent mixed peripheral nerves normally have a characteristic architecture of myelinated and unmyelinated axons. Myelinated axons have a one-to-one relationship with their Schwann cells, and within the basal lamina of a Schwann cell there is only one myelinated axon. In contrast, multiple unmyelinated axons are ensheathed within a single basal lamina of a Schwann cell and this structure is called a Remak bundle. Electron microscopy showed normal Remak bundles in the distal plantar nerves of gp120 transgenic mice. This can be seen in Figure 2 A (left); a Remak Schwann cell ensheathes several unmyelinated axons, all surrounded by one continuous basal lamina. In contrast, in DDI-treated gp120 transgenic mice, denervated Schwann cells with empty pockets of collagen within the basal lamina were seen in the distal plantar nerves (Fig. $2 A$, right), indicative of loss of unmyelinated axons. To quantify these observations, we counted the number of unmyelinated axons within each complete Remak Schwann cell basal lamina. As shown in Figure 2B, Remak bundles tended to contain fewer unmyelinated axons in DDI-treated animals (i.e., histogram shifted to the left) and there was a significant reduction in the mean number of unmyelinated axons per Remak bundle. In gp120 transgenic mice, there were 4.3 $( \pm 0.3)$ unmyelinated axons per Remak Schwann cell, but in DDI-treated gp120 transgenic mice, the mean number of unmyelinated axons per Remak bundle was $2.6( \pm 0.2)(p<0.05)$.

DDI administration does not induce axonal degeneration in the proximal sciatic nerve of gp120 transgenic mice

Patients with HIV-SN have evidence of dying back sensory axonal degeneration, with the most distal portions of long fibers being affected first. Plastic sections of proximal sciatic nerve from wild-type and gp120 transgenic mice with and without exposure to DDI revealed no evidence of Wallerian-like degeneration and normal morphology of myelinated axons (Fig. 3). Evaluation of the unmyelinated axons was done using electron microscopy and the number of unmyelinated axons per Remak Schwann cell was quantified using an unbiased sampling method as described in Materials and Methods. There was no significant difference in the normal distribution of the unmyelinated axons among groups.

\section{Behavioral and electrophysiological observations in gp120} transgenic mice treated with DDI

Behavioral testing of thermal sensation and motor function was done at baseline and after 4 weeks of oral DDI treatment. As seen in Figure $4 A$, the only group that developed mild thermal hyperalgesia was gp120 transgenic mice treated with DDI. All of the other groups had similar paw-withdrawal latency at baseline and after 4 weeks of DDI. There was no difference among groups in motor strength as evaluated by forearm grip strength measurements at baseline and after 4 weeks of DDI (Fig. 4B). Similarly, none of the animals developed weakness or coordination difficulties and all remained on the rotor-rod for $>3 \mathrm{~min}$ at both time points (data not shown).

Electrophysiological function was evaluated with motor and sensory nerve conduction studies (Table 1). There was no difference in compound motor action potential amplitude and motor distal latency among all four groups. In sensory testing there was a trend for a reduction in sensory nerve action potential ampli- 
tude in DDI-treated gp120 transgenic mice, but this did not reach statistical significance.

\section{Discussion}

HIV-SN includes two clinically identical neuropathies: distal sensory polyneuropathy (DSP), associated with advanced HIV infection per se, and antiretroviral toxic neuropathy, precipitated by the use of antiretroviral DDX drugs in patients at varying stages of HIV infection. In previous work, we established in vitro models of HIV-SN, showing that both gp120 and DDX drugs induce axonal degeneration in primary DRG neuronal cultures, albeit by different mechanisms of neurotoxicity (Keswani et al., 2003a,b, 2004). However, there has been no established in vivo rodent model of HIV-SN. This has hindered the development of therapeutic strategies for HIV-SN, which presently has no effective therapies. Here, we report the development of a rodent model of HIV-SN with distal sensory axonal degeneration as seen in HIV patients with early stages of HIV-SN.

Although 2-month-old GFAP-gp120 transgenic mice have been reported to have CNS neuropathology similar to that seen in HIV dementia, we did not detect evidence of peripheral neuropathy in these mice at that age. However, in preliminary longitudinal studies of these mice, we have seen evidence of distal axonal degeneration (a decrease in IENF density in the hind paws) beginning at 12-15 months of age (data not shown). Of interest, this finding does correlate with a published study showing evidence of cognitive impairment in GFAP-gp120 transgenic mice at 12 months of age, but not at 3 months (D'Hooge et al., 1999). It is tempting to speculate that the late-onset neuropathy that we observe in GFAP-gp120 transgenic mice is analogous to the development of DSP in patients with advanced HIV infection. However, waiting 12 to 15 months for the development of neuropathy makes this animal model not a practical one, with respect to the screening of candidate therapeutics.

Despite the demonstration by in vitro studies that DDX agents induce neuronal mitochondrial dysfunction and axonal degeneration, it has been difficult to establish an animal model of DDXinduced peripheral neuropathy. Although a model of DDC neurotoxicity in New Zealand white (NZW) rabbits has been reported, this neuropathy was described as being predominantly demyelinating with prominent involvement of motor fibers, in contrast to the sensory axonal pathology seen in HIV-infected individuals (Feldman et al., 1992; Anderson et al., 1994). Furthermore, another group failed to reproduce this neuropathy in NZW rabbits despite using high doses of DDI and d4T for 24
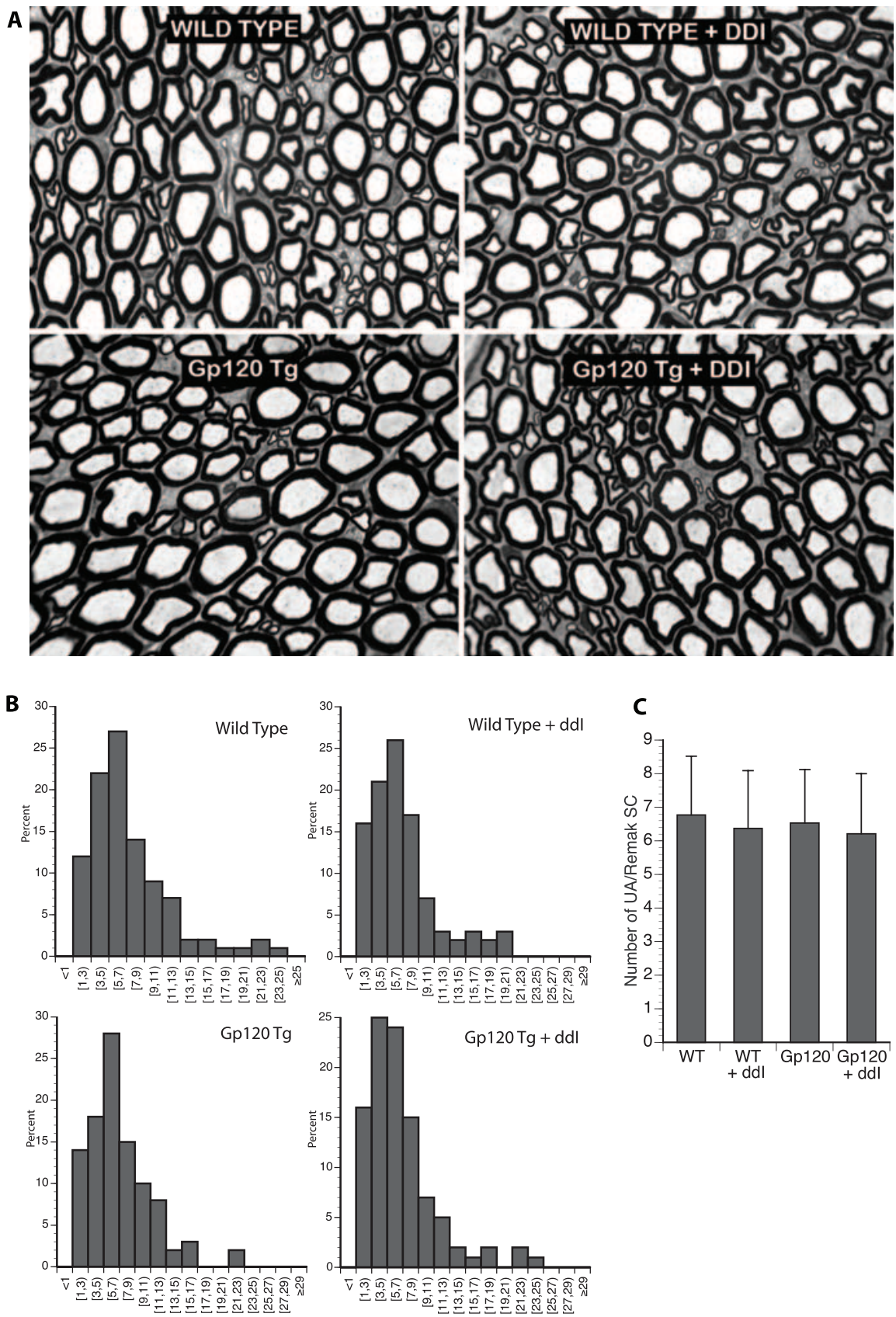

Figure 3. DDI administration does not induce axonal degeneration in the proximal sciatic nerve. $\boldsymbol{A}$, Plastic sections of proximal sciatic nerve from wild-type and gp120 transgenic mice with and without exposure to DDI revealed no abnormalities. In particular, no evidence of Wallerian-like degeneration was observed, with similar staining patterns for myelinated axons. $\boldsymbol{B}$, Histograms of unmyelinated axons showed similar patterns, suggesting that there was no significant unmyelinated axonal loss proximally. C, Mean number of unmyelinated axons per Remak bundle are shown ( $n=4-6$ animals per group). WT, Wild-type.

weeks (Warner et al., 1995). We have been unable to establish a rodent model of DDX-induced neuropathy. Despite daily intraperitoneal administration for 8 months of up to $100 \mathrm{mg} / \mathrm{kg}$ of DDC to rats, no effect on unmyelinated nerve fibers in the footpad was observed (J. C. McArthur, unpublished observation). Furthermore, in a prelicensing study, primates receiving high doses of $\mathrm{d} 4 \mathrm{~T}$ for 1 year did not develop neuropathy. These difficulties in establishing an animal model of DDX-induced peripheral neuropathy may reflect the concomitant need for HIV infection for manifestation of DDX-induced neurotoxicity. In this double-hit hypothesis, DRG neurons/sensory axons are first damaged or sensitized by viral proteins, including gp120, released 
A

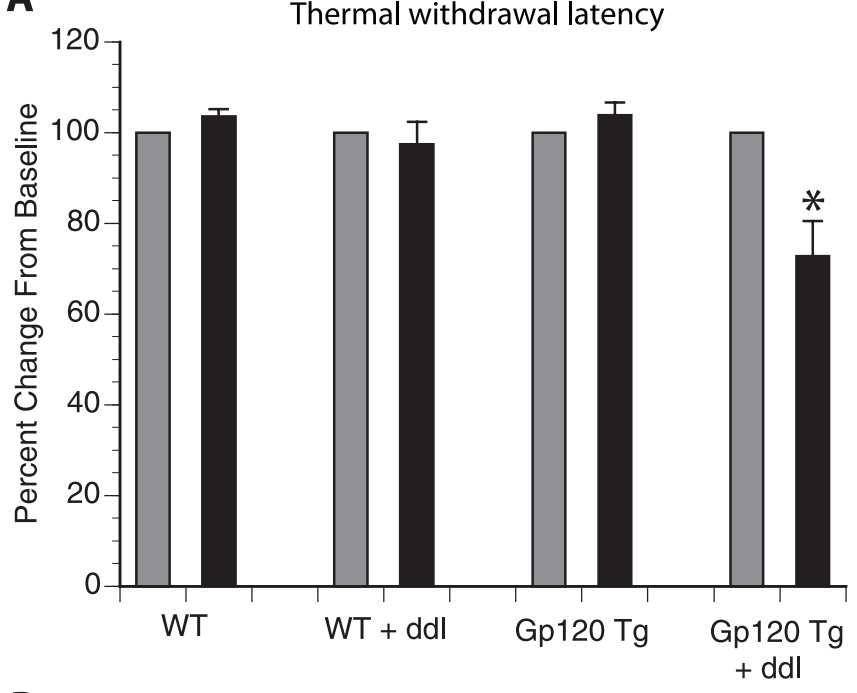

B

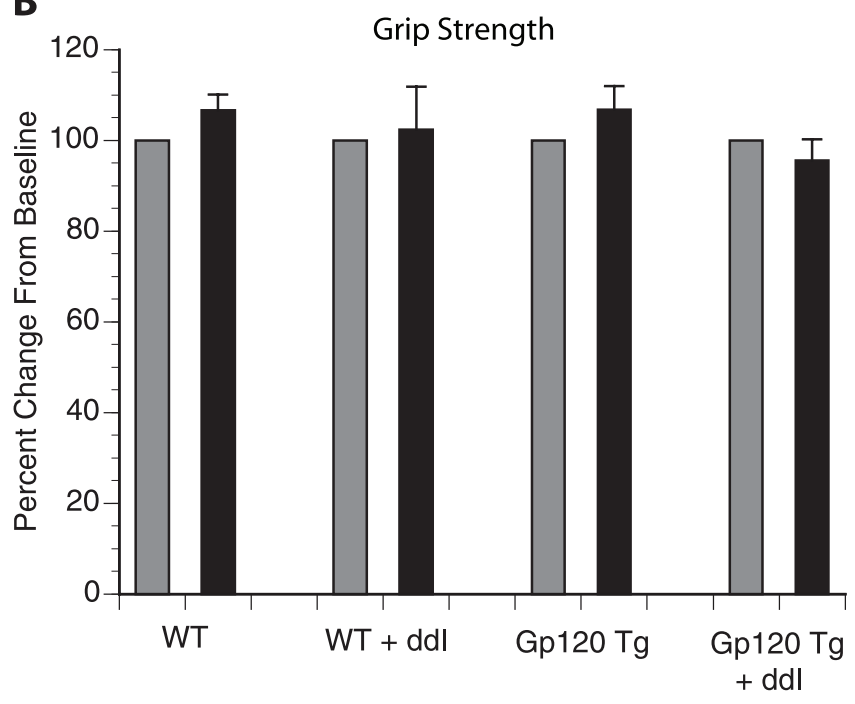

Figure 4. Thermal sensation and motor strength in gp120 transgenic mice treated with DDI. $A$, Paw withdrawal latency to thermal stimulation was done at baseline and after 4 weeks of oral DDI treatment. Only DDI-treated gp 120 transgenic mice developed thermal hyperalgesia. ${ }^{*} p<$ 0.05 compared with gp 120 transgenic mice. $\boldsymbol{B}$, Motor function using grip strength testing was done at baseline and after 4 weeks of oral DDI treatment. In both graphs, the results are expressed as a percentage change from the baseline. Gray bars denote baseline, and black bars represent repeat testing after 4 weeks of DDI or control. Error bars indicate SE.

Table 1. Motor and sensory nerve conduction studies

\begin{tabular}{lllll}
\hline & CMAP $(\mathrm{mV})$ & Motor DL $(\mathrm{s})$ & SNAP $(\mu \mathrm{V})$ & Sensory CV $(\mathrm{m} / \mathrm{s})$ \\
\hline WT & $8.9(1.5)$ & $1.9(0.1)$ & $40.8(9.5)$ & $34.9(4.4)$ \\
WT + DDI & $9.2(0.8)$ & $2.3(0.3)$ & $34.2(17.7)$ & $33.3(2.4)$ \\
gp120 Tg & $8.0(1.5)$ & $2.2(0.4)$ & $43.8(21.2)$ & $35.8(5.5)$ \\
gp120 Tg + DDI & $8.4(1.6)$ & $2.3(0.2)$ & $31.2(11.5)^{*}$ & $36.8(4.6)$ \\
\hline
\end{tabular}

Motor nerve conduction studies were done by stimulating the sciatic nerve at the sciatic notch and recording at the sciatic nerve innervated foot muscles. Sensory nerve conduction studies were done by stimulating at the base of the tail and recording $5 \mathrm{~cm}$ distally. Numbers in parenthesis denote SDs. Motor DL, Motor distal latency; sensory CV, sensory conduction velocity; WT, wild-type; Tg, transgenic. ${ }^{*} p=0.6$ compared with gp $120 \mathrm{Tg}$.

from infiltrating HIV-infected macrophages, and are then further compromised by DDX-induced mitochondrial toxicity.

Consistent with this hypothesis, we show that oral administration for 1 month of DDI to 2-month-old GFAP-gp120 transgenic mice, but not wild-type mice, resulted in distal degeneration of unmyelinated sensory fibers. This was reflected by reduced IENF densities in the plantar footpad, and reduced numbers of unmyelinated axons per Remak bundle in distal plantar nerves. In contrast, we saw no evidence of axonal degeneration in the proximal sciatic nerve of these animals. This reflects the histopathology observed in patients with HIV-SN (i.e., a dying back pattern of sensory axonal degeneration with prominent involvement of unmyelinated fibers). These histopathological observations correlated with electrophysiological and behavioral testing in these mice. There was no significant effect on the motor nerve function as measured by grip strength measurements and motor nerve conduction studies. Sensory testing for thermal sensation showed that only the gp120 transgenic mice treated with DDI developed mild thermal hyperalgesia, and although there was a trend for a reduction in tail sensory nerve action potential amplitudes, this was a not a statistically significant finding. These observations correlate with clinical findings in HIV patients with early sensory neuropathy. Often the patients present with painful dysesthesias but electrophysiological studies are within normal limits and the only objective abnormality is reduction in IENF density (Polydefkis et al., 2002), suggesting that early HV-SN is limited to the distal axons of unmyelinated sensory nerves.

Difficulty in establishing a pure DDX-induced neuropathy may have multiple causes. The DDX drugs are actually prodrugs that need to be converted intracellularly into the 5 '-triphosphate form to be active (Waqar et al., 1984; Furman et al., 1986). It is possible that conversion from a prodrug in rodent cells, especially in neurons, may be limited. There are differences in the conversion rate among different cell types within a species and probably among species (Waqar et al., 1984; Cooney et al., 1986; Furman et al., 1986; Starnes and Cheng, 1987). In our study, we had to use a much higher dose (25 mg/d per mouse) than that used clinically in HIV patients $(400-500 \mathrm{mg} / \mathrm{d})$. However, we do not have an independent biomarker of the intracellular effects of DDX drugs in this study to confidently state that this oral dose is equivalent to the oral dose in humans. Other researchers have looked for biomarkers for use of DDX drugs and development of neurological complications in humans. For example, Cherry et al. (2002) reported that DDX drug use correlated with reduction in mitochondrial DNA content in subcutaneous fat tissue in HIV patients, but there was no correlation with development of neuropathy in these patients. This observation further supports the hypothesis that DDX neurotoxicity may not be directly related to the ability of DDX drugs inhibiting the mitochondrial DNA polymerase- $\gamma$ (for review, see Höke and Cornblath, 2005).

In summary, we have established a rodent model of HIV-SN that is readily amenable to screening strategies for potential therapeutic agents. It is hoped that this model will allow the development of effective therapies for HIV-SN, which are currently sorely needed. Furthermore, a more detailed examination of the cellular changes in this animal model may allow development of biomarkers and better understanding of the pathophysiology of HIV-SN.

\section{References}

Anderson TD, Davidovich A, Feldman D, Sprinkle TJ, Arezzo J, Brosnan C, Calderon RO, Fossom LH, DeVries JT, DeVries GH (1994) Mitochondrial schwannopathy and peripheral myelinopathy in a rabbit model of dideoxycytidine neurotoxicity. Lab Invest 70:724-739.

Apostolski S, McAlarney T, Quattrini A, Levison SW, Rosoklija G, Lugaressi A, Corbo M, Sadiq SA, Lederman S, Hays AP, et al (1993) The gp120 glycoprotein of human immunodeficiency virus type 1 binds to sensory ganglion neurons. Ann Neurol 34:855-863.

Cherry CL, Gahan ME, McArthur JC, Lewin SR, Hoy JF, Wesselingh SL (2002) Exposure to dideoxynucleosides is reflected in lowered mito- 
chondrial DNA in subcutaneous fat. J Acquir Immune Defic Syndr 30:271-277.

Cooney DA, Dalal M, Mitsuya H, McMahon JB, Nadkarni M, Balzarini J, Broder S, Johns DG (1986) Initial studies on the cellular pharmacology of 2',3-dideoxycytidine, an inhibitor of HTLV-III infectivity. Biochem Pharmacol 35:2065-2068.

Dawson VL, Dawson TM, Uhl GR, Snyder SH (1993) Human immunodeficiency virus type 1 coat protein neurotoxicity mediated by nitric oxide in primary cortical cultures. Proc Natl Acad Sci USA 90:3256-3259.

D’Hooge R, Franck F, Mucke L, De Deyn PP (1999) Age-related behavioural deficits in transgenic mice expressing the HIV-1 coat protein gp120. Eur J Neurosci 11:4398-4402.

Feldman D, Brosnan C, Anderson TD (1992) Ultrastructure of peripheral neuropathy induced in rabbits by $2^{\prime}, 3^{\prime}$-dideoxycytidine. Lab Invest 66:75-85.

Furman PA, Fyfe JA, St Clair MH, Weinhold K, Rideout JL, Freeman GA, Lehrman SN, Bolognesi DP, Broder S, Mitsuya H, Barry DW (1986) Phosphorylation of 3 '-azido-3'-deoxythymidine and selective interaction of the $5^{\prime}$-triphosphate with human immunodeficiency virus reverse transcriptase. Proc Natl Acad Sci USA 83:8333-8337.

Höke A, Cornblath DR (2005) Peripheral neuropathies in human immunodeficiency virus infection. In: Peripheral neuropathy, Ed 4 (Dyck PJB, Thomas PK, eds). Philadelphia: Saunders.

Höke A, Ho T, Crawford TO, LeBel C, Hilt D, Griffin JW (2003) Glial cell line-derived neurotrophic factor alters axon schwann cell units and promotes myelination in unmyelinated nerve fibers. J Neurosci 23:561-567.

Hymson DL, Hynes MD (1982) Evidence that ethanol-induced impairment of roto-rod performance is not mediated by opioid mechanisms. Prog Neuropsychopharmacol Biol Psychiatry 6:159-165.

Keswani SC, Pardo CA, Cherry CL, Höke A, McArthur JC (2002) HIVassociated sensory neuropathies. AIDS 16:2105-2117.

Keswani SC, Chander B, Hasan C, Griffin JW, McArthur JC, Höke A (2003a) FK506 is neuroprotective in a model of antiretroviral toxic neuropathy. Ann Neurol 53:57-64.

Keswani SC, Polley M, Pardo CA, Griffin JW, McArthur JC, Höke A (2003b) Schwann cell chemokine receptors mediate HIV-1 gp120 toxicity to sensory neurons. Ann Neurol 54:287-296.

Keswani SC, Leitz GJ, Höke A (2004) Erythropoietin is neuroprotective in models of HIV sensory neuropathy. Neurosci Lett 371:102-105.

Levy D, Höke A, Zochodne DW (1999) Local expression of inducible nitric oxide synthase in an animal model of neuropathic pain. Neurosci Lett 260:207-209.

Levy D, Tal M, Höke A, Zochodne DW (2000) Transient action of the endothelial constitutive nitric oxide synthase (ecNOS) mediates the development of thermal hypersensitivity following peripheral nerve injury. Eur J Neurosci 12:2323-2332.

Mah V, Vartavarian LM, Akers MA, Vinters HV (1988) Abnormalities of peripheral nerve in patients with human immunodeficiency virus infection. Ann Neurol 24:713-717.

McCarthy BG, Hsieh ST, Stocks A, Hauer P, Macko C, Cornblath DR, Griffin JW, McArthur JC (1995) Cutaneous innervation in sensory neuropathies: evaluation by skin biopsy. Neurology 45:1848-1855.

McKeown B, Geeseman R, Heyward V (1975) Comparison of the Stoelting hand grip dynamometer and linear voltage differential transformer for measuring maximal grip strength. Res Q 46:262-266.

Miller RG, Parry GJ, Pfaeffl W, Lang W, Lippert R, Kiprov D (1988) The spectrum of peripheral neuropathy associated with ARC and AIDS. Muscle Nerve 11:857-863.

Mucke L, Abraham CR, Ruppe MD, Rockenstein EM, Toggas SM, Mallory M, Alford M, Masliah E (1995) Protection against HIV-1 gp120-induced brain damage by neuronal expression of human amyloid precursor protein. J Exp Med 181:1551-1556.

Pardo CA, McArthur JC, Griffin JW (2001) HIV neuropathy: insights in the pathology of HIV peripheral nerve disease. J Peripher Nerv Syst 6:21-27.

Polydefkis M, Yiannoutsos CT, Cohen BA, Hollander H, Schifitto G, Clifford DB, Simpson DM, Katzenstein D, Shriver S, Hauer P, Brown A, Haidich AB, Moo L, McArthur JC (2002) Reduced intraepidermal nerve fiber density in HIV-associated sensory neuropathy. Neurology 58:115-119.

Starnes MC, Cheng YC (1987) Cellular metabolism of $2^{\prime}, 3^{\prime}$ dideoxycytidine, a compound active against human immunodeficiency virus in vitro. J Biol Chem 262:988-991.

Toggas SM, Masliah E, Rockenstein EM, Rall GF, Abraham CR, Mucke L (1994) Central nervous system damage produced by expression of the HIV-1 coat protein gp120 in transgenic mice. Nature 367:188-193.

Waqar MA, Evans MJ, Manly KF, Hughes RG, Huberman JA (1984) Effects of $2^{\prime}, 3^{\prime}$-dideoxynucleosides on mammalian cells and viruses. J Cell Physiol 121:402-408.

Warner WA, Bregman CL, Comereski CR, Arezzo JC, Davidson TJ, Knupp CA, Kaul S, Durham SK, Wasserman AJ, Frantz JD (1995) Didanosine (ddl) and stavudine (d4T): absence of peripheral neurotoxicity in rabbits. Food Chem Toxicol 33:1047-1050. 